EPV267/\#604 APPLICABILITY OF PRE-OPERATIVE PATIENT REPORTED DUKE ACTIVITY SCALE INDEX (DASI) IN PREDICTION OF POSTOPERATIVE COMPLICATIONS IN GYNAECOLOGICAL ONCOLOGY

'L Sevinyan*, 'A Tailor, ${ }^{2} \mathrm{P}$ Prabhu, ${ }^{3} \mathrm{P}$ Williams, ${ }^{1} \mathrm{~T}$ Madhuri. ${ }^{1}$ Royal Surrey Hospital NHS Foundation Trust, Gynaeoncology, Guildford, UK; ${ }^{2}$ Royal Surrey Hospital NHS Foundation Trust, Anaesthesiology, Guildford, UK; ${ }^{3}$ University of Surrey, Medical Statistics, Guildford, UK

10.1136/ijgc-2021-IGCS.338

Objectives Increase in the incidence of gynaecological cancers has resulted in increased operations, specifically in patients with multiple comorbidities. This is often associated with higher rates of postoperative mortality and morbidity and presents a challenge with an unmet need for an accurate, personalised risk prediction. DASI is a self-reported 12 item scale questionnaire based around commonly performed activities of daily living. This study investigates the accuracy of DASI in preoperative prediction of postoperative outcomes in gynaeoncology.

Methods A retrospective cohort study of 330 patients who had undergone an operative treatment. All patients had completed the DASI questionnaire prior to their consultation. Actual postoperative 30 day complications and the length of stay recorded. DASI was then compared with the occurrence of postoperative complications.

Results 181 patients underwent robotic procedure, 37 - laparoscopic and 112 - open surgery. Our results showed that the higher DASI score the less likely patients were to have postoperative complications. This result was statistically significant with odds ratio of 0.974 and confidence interval between 0.958 and 0.991 . We were also able to demonstrate that for every 10 points further up the DASI score a patient was 0.768 times less likely to have a postoperative complication. Hence general morbidity prediction of DASI score has been found to statistically significantly predict postoperative complications (AUC-0.700).

Conclusions Our study has shown that DASI score is a useful predictive tool of perioperative estimation of postoperative complications in gynaeoncology. Further analysis with a larger sample size and a multicentre prospective study is currently underway to validate the findings.

\section{EPV268/\#642 ROLE OF ROBOTIC SURGERY FOR INTERVAL DEBULKING OF OVARIAN CANCER AFTER NEOADJUVANT CHEMOTHERAPY}

J Press*, A Bondurant, C Drescher, F Musa, C Shah, D Veljovich, N Kretzer. Swedish Cancer Institute Gynecologic Oncology and Pelvic Surgery, Gynecologic Oncology and Pelvic Surgery, Seattle, USA

\subsection{6/ijgc-2021-IGCS.339}

Objectives Compared with primary debulking surgery, treating ovarian cancer with neoadjuvant chemotherapy (NAC) followed by interval debulking surgery (IDS) results in similar outcomes, while showing significantly less surgical morbidity. To further reduce surgical morbidity, surgeons have followed NAC with minimally invasive Robotic (R-IDS).

Methods This single institution, retrospective study evaluated patients having R-IDS after NAC for newly diagnosed advanced stage (III or IV) ovarian cancers between 20062016. Outcomes were compared between these 16 Robotic
IDS and 16 matched-cases of traditional Open laparotomy (OIDS)

Results One conversion from planned R-IDS to O-IDS due to inability to adequately ventilate. Age for R-IDS was 57 (4891) vs 66 (48-83) for O-IDS. Surgical data for R-IDS versus O-IDS showed: optimal cytoreduction $14 / 16$ (87\%) vs $15 / 16$ (94\%), intra-op blood transfusions $0 / 16$ vs $4 / 16$ (25\%), operative time (136 $\mathrm{min}, 75-250)$ vs (206 $\mathrm{min}, 128-356)$, and blood loss $98(25-250)$ vs 250 (50-600), length of stay 28 hours (21-216) vs 99 hours (67-247). Post-operatively for RIDS there were no major complications, and no ICU admissions, while O-IDS had 5 wound complications, 1 pneumonia. Thirteen of R-IDS had comprehensive follow-up data allowing analysis of progression-free survival, which ranged from 4 to 32 months, with a median PFS 15 months, and 7/13 (54\%) died of disease.

Conclusions The use of NAC before IDS has become more prevalent since publication of trials showing similar oncologic outcome to primary debulking with less morbidity. Our series supports feasibility of using a R-IDS to minimize surgical morbidity, while maintaining oncologic outcome.

\section{EPV269/\#87 PREOPERATIVE ANEMIA IN GYNECOLOGIC ONCOLOGY PATIENTS: ARE WE OPTIMIZING OUR PATIENTS?}

${ }^{1}$ E Spenard*, ${ }^{2} Y$ Lin, ${ }^{3} \mathrm{~A}$ Covens, ${ }^{3} \mathrm{~L}$ Gien, ${ }^{3} \mathrm{D}$ Vicus. ${ }^{1}$ University of Toronto, Gynecologic Oncology, Toronto, Canada; ${ }^{2}$ Sunnybrook Health Sciences Center, Laboratory Medicine and Molecular Diagnostics, Toronto, Canada; ${ }^{3}$ Sunnybrook Health Sciences Centre, Gynecologic Oncology, Toronto, Canada

\subsection{6/ijgc-2021-IGCS.340}

Objectives Preoperative anemia is one of the most prevalent yet preventable negative prognostic factors in newly diagnosed gynecologic oncology patients. However, it is often inadequately diagnosed and treated. The aim of this study was to evaluate the prevalence of preoperative anemia in gynecologic oncology patients and characterize types of anemia in this population.

Methods This was a prospective cohort study of all consecutive women consented for gynecologic oncology surgery at Sunnybrook Health Sciences Centre between November 1, 2020-February 1, 2021. CBC, ferritin and iron indices were measured within 10 days of consent(range, 0-10 days). Anemia was defined as $\mathrm{Hb}<120 \mathrm{~g} / \mathrm{L}$, absolute iron-deficiency as ferritin $<30 \mathrm{ng} / \mathrm{mL}$, absolute iron-deficiency in inflammatory setting as ferritin $30-100 \mathrm{ng} / \mathrm{mL}$ with transferrin saturation (TSAT) $<20 \%$, low iron stores as ferritin $<100 \mathrm{ng} / \mathrm{mL}$ with TSAT $>20 \%$ and functional iron-deficiency as ferritin $<300 u g / L$ with TSAT $<20 \%$.

Results 133 patients were included. Anemia occurred in 32\% $(n=43)$ of patients. It affected $56 \%$ of patients with ovarian cancer, $37 \%$ with endometrial cancer, 5\% with cervical cancer and $6 \%$ with vulvar cancer. The overall mean $\mathrm{Hb}$ level was $126 \mathrm{~g} / \mathrm{L}($ range, $71-152 \mathrm{~g} / \mathrm{L})$. The overall prevalence of mild(110 $119 \mathrm{~g} / \mathrm{L})$, moderate $(80-109 \mathrm{~g} / \mathrm{L})$ and severe $(<80 \mathrm{~g} / \mathrm{L})$ anemia were $42 \%, 47 \%$ and $12 \%$ respectively. Functional iron-deficiency anemia was the most common cause of anemia(33\%), followed by absolute iron-deficiency(21\%). $8 \%(n=10)$ had received neoadjuvant chemotherapy.

Conclusions One third of patients undergoing gynecologic oncology surgery had anemia. Populations of focus should include ovarian and endometrial cancer patients, due to high 
rate of preoperative moderate to severe anemia and potential for improvement. This represents an opportunity for patientsafety initiatives.

\section{EPV270/\#88 OPTIMIZING THE SCREENING AND MANAGEMENT OF PREOPERATIVE ANEMIA PRIOR TO GYNECOLOGIC ONCOLOGY SURGERY (OPRA): A QUALITY IMPROVEMENT INITIATIVE}

${ }^{1} E$ Spenard*, ${ }^{2} Y$ Lin, ${ }^{3} \mathrm{~A}$ Covens, ${ }^{3} \mathrm{~L}$ Gien, ${ }^{2} \mathrm{~J}$ Callum, ${ }^{2} \mathrm{R}$ Tano, ${ }^{2} \mathrm{~S}$ Jadunandan, ${ }^{4} \mathrm{P}$ Trbovich, ${ }^{3} \mathrm{D}$ Vicus. ${ }^{1}$ University of Toronto, Gynecologic Oncology, Toronto, Canada; ${ }^{2}$ Sunnybrook Health Sciences Center, Laboratory Medicine and Molecular Diagnostics, Toronto, Canada; ${ }^{3}$ Sunnybrook Health Sciences Centre, Gynecologic Oncology, Toronto, Canada; ${ }^{4}$ University of Toronto, Institute of Health Policy, Management and Evaluation, Toronto, Canada

\subsection{6/ijgc-2021-IGCS.341}

Objectives Preoperative anemia is an established negative prognostic factor in gynecologic oncology patients. However, it is often undetected and inadequately treated. The aim of this quality-improvement initiative was to increase the treatment rate of preoperative anemia in gynecologic oncology patients undergoing surgery at a large tertiary centre.

Methods This was a time-series study between October 1, 2019-April 1, 2021. All gynecologic oncology patients consented for surgery at our institution were included. From October to December 2020, three interventions were implemented: a tracking system for patients consented for surgery, standardized screening for preoperative anemia, and automatic referral to patient blood management program(PBMP). The primary outcome was the treatment rate of patients with anemia receiving intravenous iron or erythropoiesis-stimulating agent prior to surgery. Secondary outcomes were perioperative blood transfusion rate, postoperative nadir hemoglobin $(\mathrm{Hb})$ level and length of stay(LOS). Process measures included screening and PBMP referral rates. Balancing measures included treatment complications and patient satisfaction.

Results of the 151 pre-intervention and 229 post-intervention patients, $32 \%(n=121)$ had anemia. After intervention, screening rates and PBMP referral rates increased from $2 \%$ to $82 \%(\mathrm{p}<0.00001)$ and $9 \%$ to $80 \%(\mathrm{p}<0.00001)$, respectively. The treatment rate increased from $7 \%$ to $31 \%(\mathrm{p}<0.009)$. The transfusion rate decreased from $20 \%$ to $12 \%(\mathrm{p}=0.027)$. The postoperative nadir $\mathrm{Hb}$ level increased from 92 to $96 \mathrm{~g} / \mathrm{L}$ $(p=0.049)$. There was no difference in LOS across all surgeries. No treatment associated complications were reported. The median patient satisfaction score was 4.5 on a five-point Likert scale.

Conclusions Optimizing treatment of preoperative anemia in gynecologic oncology patients significantly decreased transfusion rate, without affecting LOS.

\section{EPV271/\#98 EFFECT OF SURGICAL MODALITY ON THE OCCURRENCE OF VAGINAL VAULT DEHISCENCE}

${ }^{1}$ YJ Lee*, ${ }^{2}$ KJ Eoh, ${ }^{1}$ Y-N Kim, ${ }^{1}$ YJ Rhee, ${ }^{3}$ YJ Lee, ${ }^{3}$ J-Y Lee, ${ }^{3}$ EJ Nam, ${ }^{3}$ SW Kim, ${ }^{3}$ S Kim, ${ }^{3} Y \mathrm{~T}$ Kim. ' ${ }^{1}$ Severance hospital, Obstetrics and Gynecology, Seoul, Korea, Republic of; ${ }^{2}$ Yongin Severance hospital, Obstetrics and Gynecology, Gyeonggido, Korea, Republic of;

${ }^{3}$ Yonsei University College of Medicine, Dept. of Ob/gyn, Seoul, Korea, Republic of
Objectives This study aimed to analyze the incidence and risk factors of vault dehiscence after hysterectomy with respect to the mode of operation and the time to occurrence.

Methods We conducted a retrospective study including 6,530 patients who underwent hysterectomy at Severance Hospital

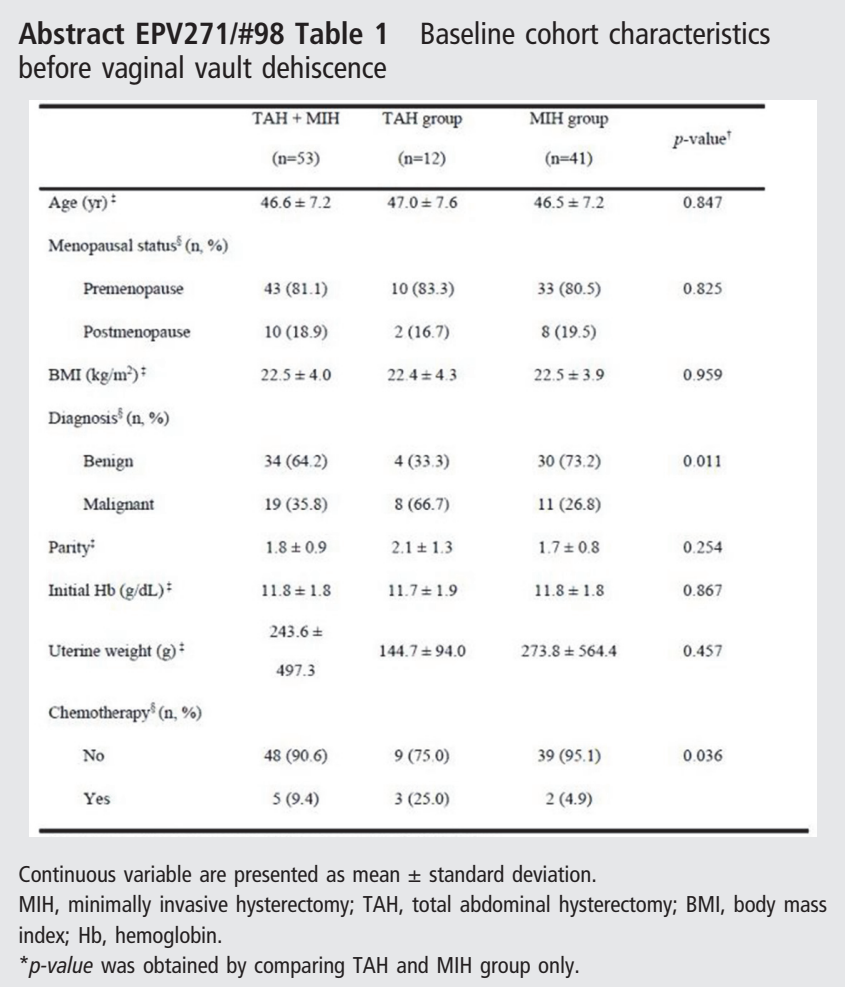

Abstract EPV271/\#98 Table 2 Comparison between early and late occurrence in patients with vaginal vault dehiscence

\begin{tabular}{|c|c|c|c|}
\hline & $\begin{array}{l}\text { Early occurrence } \\
<8 \text { weeks }\end{array}$ & $\begin{array}{l}\text { Late occurrence } \\
\geq 8 \text { weeks }\end{array}$ & $p$-value \\
\hline \multicolumn{4}{|l|}{ Baseline cohort characteristics } \\
\hline $\operatorname{Age}(\mathrm{yr})$ & $45.3 \pm 1.3$ & $48.3 \pm 1.5$ & 0.130 \\
\hline \multicolumn{4}{|l|}{ Menopausal status } \\
\hline Premenopause & $27(93.1)$ & $16(66.7)$ & 0.031 \\
\hline Postmenopause & $2(6.9)$ & $8(333)$ & \\
\hline $\mathrm{BMI}\left(\mathrm{kg} / \mathrm{m}^{2}\right)$ & $23.2 \pm 0.8$ & $21.6 \pm 06$ & 0.123 \\
\hline Uterine weight (g) & $322.3 \pm 645.2$ & $137.3 \pm 91.2$ & 0211 \\
\hline \multicolumn{4}{|l|}{ Diagnosis } \\
\hline Benign & $18(62.1)$ & $16(66.7)$ & 0.728 \\
\hline Malignant & $11(379)$ & $8(33.3)$ & \\
\hline \multicolumn{4}{|l|}{ Chemotherapy } \\
\hline No & $26(89.7)$ & $22(21.7)$ & 1.000 \\
\hline Yes & $3(10.3)$ & $2(8.3)$ & \\
\hline \multicolumn{4}{|l|}{ Mode of hysterectomy } \\
\hline Minimally invasive surgery & $21(72.4)$ & $20(83.3)$ & 0.344 \\
\hline Open & $8(27.6)$ & $4(16.7)$ & \\
\hline \multicolumn{4}{|l|}{ Management after vaginal vault dehiscence } \\
\hline \multicolumn{4}{|l|}{ Surgical repairT } \\
\hline Yes & $15(517)$ & $23(95.8)$ & 0.000 \\
\hline No & $14(48.3)$ & $1(4.2)$ & \\
\hline \multicolumn{4}{|l|}{ Method of dehiscence repair } \\
\hline Minimally invasive surgery & $2(6.9)$ & $13(54.2)$ & 0.000 \\
\hline Open & $1(3.4)$ & $1(4.2)$ & \\
\hline Vaginal & $12(41.4)$ & $9(37.5)$ & \\
\hline Embolization & $1(3.4)$ & $0(0.0)$ & \\
\hline Conservative & $13(44.8)$ & $1(4.2)$ & \\
\hline Hospitalized days after dehiscence (day) & $7.1 \pm 5.2$ & $49 \pm 2.6$ & 0.149 \\
\hline
\end{tabular}

Continuous variable are presented as mean \pm standard deviation. BMI, body mass index; MIS, minimally invasive surgery. tSurgical repair includes Minimally invasive surgery, Open and vaginal approach for repair. 